\title{
Follicular Helper T (Tfh) Cells in Autoimmune Diseases and Allograft Rejection
}

\author{
Yun-Hui Jeon ${ }^{2}$ and Youn Soo Choi ${ }^{1,2,3 *}$ \\ ${ }^{1}$ Transplant Research Institute, Department of Medicine, Seoul National University College of Medicine, ${ }^{2}$ Department of Biological \\ Sciences, Seoul National University Graduate School, ${ }^{3}$ Seoul National University Hospital, Seoul 03080, Korea
}

Production of high affinity antibodies for antigens is a critical component for the immune system to fight off infectious pathogens. However, it could be detrimental to our body when the antigens that B cells recognize are of self-origin. Follicular helper $\mathrm{T}$, or Tfh, cells are required for the generation of germinal center reactions, where high affinity antibody-producing B cells and memory B cells predominantly develop. As such, Tfh cells are considered as targets to prevent B cells from producing high affinity antibodies against self-antigens, when high affinity autoantibodies are responsible for immunopathologies in autoimmune disorders. This review article provides an overview of current understanding of Tfh cells and discusses it in the context of animal models of autoimmune diseases and allograft rejections for generation of novel therapeutic interventions.

[Immune Network 2016;16(4):219-232]

Keywords: Tfh, Germinal center reactions, Autoantibodies, Autoimmunity, Allograft rejection

\section{INTRODUCTION}

The immune system is composed of various types of white blood cells (leukocytes and lymphocytes) and regulates myriad immune responses to protect the body against infectious pathogens or harmful substances as well as to modulate immune homeostasis. Among them, $B$ cells and $T$ cells generate immune responses in antigen specific manners using antigen-recognizing $\mathrm{B}$ cell or $\mathrm{T}$ cell surface receptors. B cell receptor (BCR) and T cell receptor (TCR) form through irreversible recombination processes on the genes encoding the $\mathrm{V}$ (variable), D (diversity), and J (joining) segments of BCR and TCR, respectively. Through this process, developing B and $\mathrm{T}$ cells theoretically recognize more than about $10^{11}$ different antigens (1), which means some of them could recognize antigens expressed by our own body. For this, the immune system has evolutionarily elaborated checkpoints (central and peripheral tolerance) to keep the B and T cells not responding to our own antigens (2). However, while it is not clear whether our immune system is still in processes of evolutionary selection, there exist many forms of immune disorders that are triggered by B cells and $\mathrm{T}$ cells, which we call autoimmune diseases.

B lymphopoiesis occurs when B cell progenitors develop from common lymphoid progenitors by surface expression

Received on June 8, 2016. Revised on July 25, 2016. Accepted on August 2, 2016.

(C) This is an open access article distributed under the terms of the Creative Commons Attribution Non-Commercial License (http://creativecommons. org/licenses/by-nc/4.0) which permits unrestricted non-commercial use, distribution, and reproduction in any medium, provided the original work is properly cited.

*Corresponding Author. Youn Soo Choi, Transplantation Research Institute, Department of Medicine, Seoul National University College of Medicine, Department of Biological Sciences, Seoul National University Graduate School, Seoul National University Hospital, 103 Daehak-ro, Jongno-gu, Seoul 03080, Korea. Tel: 82-2-3668-7377; Fax: 82-2-3673-2167; E-mail: younsoo94@snu.ac.kr

Abbreviations: AID, activation induced cytidine deaminase; GC, germinal center; SLE, systemic lupus erythematosus; FDCs, follicular dendritic cells; Tfh, follicular helper T cells; Bcl6, B cell lymphoma 6; RA, rheumatoid arthritis; ACPA, anti-citrullinated peptide antibody; MS, multiple sclerosis; MOG, myelin oligodendrocyte glycoprotein; EAE, experimental autoimmune encephalomyelitis; MG, myasthenia gravis; EAMG, experimental autoimmune myasthenia gravis; SS, Sjogren's syndrome; DSA, donor specific antibody 
of B220 (3), a B cell lineage marker. Through a successive recombination on the immunoglobulin heavy chain and light chain genes to form functional B cell receptors (BCRs), $\mathrm{B}$ cell progenitors develop into immature and mature $\mathrm{B}$ cells (3). Along these processes, B cells get educated not to respond to self-antigens (in a process called "central tolerance"); B cells that acquire BCRs binding strongly to antigens (self-reactive B cells) expressed by stromal cells in the bone marrow undergo apoptosis, a process known as negative selection (4). While substantial pool of self-reactive B cells can be removed by central tolerance, self-reactive B cells are certainly present in periphery but remain biologically inert (5). Peripheral tolerance functions to further make sure self-reactive B cells do not differentiate into antibody secreting plasma cells. When self-reactive $\mathrm{B}$ cells get activated and differentiate into plasma cells, immunopathological conditions can be triggered by the formation of immune complex of autoantibodies, which contributes to autoimmune disorders. While multiple genetic and environmental risk factors play roles in triggering autoimmune diseases, the production of autoantibodies against various selfantigens is strongly correlated with etiology and severity of autoimmune disorders (6).

In humans and mice, several types of B cells contribute to antibody production (7). While it requires more evidence to identify human counterpart, murine B-1 cells, together with marginal zone B cells, produce antibodies in the absence of $\mathrm{T}$ cell help (thymus-independent [TI] $\mathrm{Ab}$ responses) $(8,9)$. While these cells are major players to produce antibodies quickly after infections to limit the early burst of replication of pathogens, B (follicular B or B-2) cells are ones that elicit much stronger antibody responses by forming long-lived plasma cells and memory $B$ cells. These effector B cells develop mostly from germinal center reactions, where $B$ cells acquire affinity maturation (somatic hyper-mutation) and isotype switching by spatio-temporal induction of Aicda in germinal center $\mathrm{B}$ cells, a gene that encode activation induced cytidine deaminase (AID) (10). As such, germinal center reaction is an ideal target for modulation of strong antibody responses to antigen, regardless of its origin.

Helper $\mathrm{CD} 4^{+} \mathrm{T}$ cells differentiate into effector cells, such as $\mathrm{T}$ helper 1 (Th1), Th2, Th17, or regulatory $\mathrm{T}$ (Treg) cells, and are in charge of clearing intracellular pathogens (Th1), helminthes (Th2), or bacteria (Th17), or associated with allergic responses (Th2) or homeostasis of immune cells (Treg) (11). Follicular helper $\mathrm{T}$ (Tfh) cells are effector $\mathrm{CD}^{+} \mathrm{T}$ cells that were recently identified due to specialized functions to help B cells form germinal center reactions (12). Germinal center reaction develops in Tfh cell dependent manners (13-15), and the magnitude of germinal center B cells developing in the secondary lymphoid tissues is positively regulated by the number of Tfh cells that develop in the same lymphoid tissue after immunization $(16,17)$. Taken together, these studies strongly indicate that $\mathrm{Tfh}$ differentiation needs to be unveiled for the regulation of germinal center reactions and strong antibody responses. Most interestingly, it was demonstrated that the autoantibody production and autoimmune pathologies were ameliorated by inhibiting $\mathrm{Tfh}$ differentiation or by preventing interaction of $\mathrm{Tfh}$ cells and germinal center B cells using mouse models of autoimmune diseases (18).

Given critical roles of Tfh cells for generation of strong Abs against self-antigens, we discuss here about the current understanding of Tfh differentiation and how we can make use of animal models to develop new drugs that target $\mathrm{Tfh}$ differentiation to cure autoimmune disorders. Also, we briefly cover and discuss recent findings about biological functions of Tfh cells in the context of transplantation.

\section{MAIN}

\section{Germinal centers}

Antibody production is one of the most important features of the immune system in host protection against deadly infectious diseases (19). However, abnormal regulation of antibody production by B cells leads to antibody-mediated immune diseases such as autoimmune disorders. More than 100 types of antibodies against self antigens are present in humans who suffer from systemic lupus erythematosus (SLE) (20). While B cells produce antibodies in several different ways, antibodies that bind to antigens with high affinity are formed predominantly through germinal center reactions (10). Through strong induction of AID (21), which introduces point mutations across the genome, proliferating B cells in the dark zone of germinal centers could express B cell receptors that have increased or decreased affinity to antigens. Then newly formed B cells migrate toward light zone, where follicular dendritic cells (FDCs) present unprocessed antigens through Fc receptors (22). B cells that express higher affinity to antigens are now superior to collect antigens from FDCs, process antigens into peptides for presenting to helper $\mathrm{T}$ cells on MHC class II molecules. B cells can survive and further proliferate in dark zone only when $\mathrm{B}$ cells receive help signals from helper T cells. While there are not clear answers for how germinal center B cells are instructed 
to form plasma cells or memory B cells inside germinal centers, germinal center B cells acquire higher and higher affinity to Ags through repeating these processes (23). Thus, given critical roles of high affinity antibodies in the context of immune protection as well as immune disorders, it is critical to understand how the germinal center reactions are regulated by helper $\mathrm{T}$ cells.

\section{Follicular helper T cells}

When the immune system was characterized by effector functions of T helper 1 (Th1) versus Th2 cells, T helper 2 (Th2) cells were believed to modulate antibody-mediated humoral immunity, whereas Th1 cells are in charge of cellular immune responses (24). However, the field faced a big conundrum as germinal centers were normally found in mice deficient in IL4, a key signaling molecule for Th2 differentiation (25). And a clear answer for the gap in our knowledge of $\mathrm{T}$ cell help of $\mathrm{B}$ cell immune responses has not been put forward until when $\mathrm{CD} 4^{+} \mathrm{T}$ cells were identified inside germinal centers for the first time (26). Helper T cells residing in germinal centers of $\mathrm{B}$ cell follicles were reported to express high level of CXCR5, the rector for CXCL13, a chemokine critical for the migration of B cells into B cell follicles (26). Gene expression profile analysis from multiple research groups revealed that CXCR5-expressing helper T cells exhibit different gene expression pattern from those of other effector helper T cells, such as Th1, Th2, Th17 and regulatory $\mathrm{T}$ cells, and therefore might be unique $\mathrm{CD}^{+} \mathrm{T}$ cell subset (27-29). And these CXCR5 expressing helper $\mathrm{T}$ cells were coined as follicular helper $\mathrm{T}$ cells, or Tfh cells in short. However, the uniqueness of Tfh cells as a separate subset of effector helper $\mathrm{T}$ cells was argued due mostly to promiscuous features of Tfh cells (12).

Fate determining regulators are critical to specify naïve $\mathrm{CD} 4^{+} \mathrm{T}$ cells to differentiate into different subsets of effector helper $\mathrm{T}$ cells. Thanks to tremendous efforts made over the past few decades, T-bet, GATA3, Ror $\gamma \mathrm{t}$ and Foxp3 were identified as master transcription factors for Th1, Th2, Th17, and regulatory $\mathrm{T}$ (Treg) cells, respectively (11). In 2009, three research groups reported almost simultaneously that Bcl6 is the master transcription factor for Tfh differentiation (13-15). Bcl6 is a transcription repressor and functions for Tfh differentiation in part by suppressing induction of genes that are critical for differentiation of helper T cells into Th1, Th2, Th17 and regulatory T cells (12). While Bcl6 is not only required for Tfh differentiation but also sufficient to push vast majority of helper $\mathrm{T}$ cells differentiating into Tfh cells in vivo (13), Bcl6 does not appear to be the only transcription factor enough to instruct $\mathrm{Tfh}$ differentiation by itself, as forced ectopic Bcl6 expression failed to induce $\mathrm{Tfh}$ differentiation from in vitro stimulated $\mathrm{CD} 4^{+}$ $\mathrm{T}$ cells (30). Moreover, while multiple laboratories reported that Tfh cells could develop by in vitro culture of $\mathrm{CD}^{+} \mathrm{T}$ cells, none of them was unfortunately reproducible, indicating that the field is still missing for key signaling molecule(s) or transcription factor(s) of the $\mathrm{Tfh}$ differentiation. As such, future studies need to further examine Tfh differentiation processes to reveal key signaling events for manipulation of the development of $\mathrm{Tfh}$ cells.

\section{Cellular targets to cure autoimmune diseases}

As discussed above, germinal center formation and high affinity antibody production by B cells could be targeted in cell intrinsic or extrinsic way, or both to restrain selfreactive $B$ cells from instigating autoantibody mediated immunological disorders. Under normal physiological environment, self-reactive B cells are kept immunologically inactive due to the peripheral tolerance and therefore hardly form germinal centers. However, antibodies found in autoimmune patients were shown to bind to self-antigens with strong affinity (31). Moreover, anti-nuclear antigen antibodies (ANA) and anti-DNA antibodies produced in autoimmune patients and mouse models exhibit signs of somatic hyper-mutation $(32,33)$, strongly indicating that germinal center reactions develop from self-reactive B cells. Indeed, aberrant formation of germinal centers and antibody secreting plasmablasts are frequently found in autoimmune patients as well as mouse models of autoimmune diseases $(34,35)$. Therefore, selfreactive $B$ cells (B cell intrinsic way) and $\boldsymbol{T}$ fh cells (B cell extrinsic way) should be examined to reveal therapeutic targets for autoimmune diseases, which are discussed below.

Self-reactive B cells: To produce antibodies against an antigen, regardless of its origin, $\mathrm{B}$ cells require to receive activation signals, which are transmitted in surface BCRdependent (Signal 1) or BCR-independent manners. The latter is mostly provided through co-stimulatory receptors expressed by B cells (Signal 2). Due to the short cytoplasmic tails of BCRs, crosslinked BCRs cannot trigger activation signals upon recognition of antigens. Instead, Signal 1 is conveyed into the cells through coreceptors, such as CD79a $(\operatorname{Ig} \alpha)$ and $C D 79 b(\operatorname{Ig} \beta)$, which harbor and use immunoreceptor tyrosine-based activation motifs (ITAMs) in the cytoplasmic tails to propagate signals downstream of BCR crosslinking (36). Signal 2 is provided by various types of co-stimulatory receptors 
including toll-like receptors (TLRs) $(37,38)$. As such, both Signal 1 and Signal 2 could be excellent targets to inhibit self-reactive B cells from forming autoantibodies. However, it could be challenging to reveal how to manipulate Signal 1, as genetic ablation of $\operatorname{Ig} \alpha$ and $\operatorname{Ig} \beta$ leads to a complete block in B cell development (39). Instead, Signal 2 seems to be relatively practical targets to suppress self-reactive B cells. TLR7, which triggers activation signal through recognition of single stranded RNA and its downstream signaling molecule MyD88, was shown to play critical roles for autoantibody production by self-reactive B cells. Using mouse models of autoimmune prone B6.Sle1b mice, Rahman and colleagues demonstrated that TLR7 is required for self-reactive B cells to form spontaneous germinal center reactions (40). While this study suggested TLR7 as a potential therapeutic target to cure autoimmune diseases, further studies are necessary to determine whether TLR7 antagonists could be developed as a novel drug to target self-reactive, but not pathogen-specific, B cells because TLR7-mediated activation signals play critical roles for B cells to elicit anti-viral immune responses (41). A recent study shed light on ways to selectively prevent self-reactive B cells from forming detrimental germinal centers. IFN- $\gamma$ receptor expression is necessary only for self-reactive B cells to form spontaneous germinal centers in autoimmune prone B6.Sle $1 b$ mice, while the lack of IFN- $\gamma$ receptor did not affect antigen-specific B cells to form germinal center responses to foreign antigens (42). While IFN- $\gamma$ seems to be an ideal target to selectively target self-reactive B cells, it needs further examination on the development of IFN- $\gamma$ inhibitors to inhibit high affinity autoantibodies. As IFN- $\gamma$ signal is crucial for clearance of pathogens by Th1 and $\mathrm{CD}^{+} \mathrm{T}$ cells, NK cells, and macrophages, IFN- $\gamma$ receptor deficient mice succumb to infection with various types of pathogens $(43,44)$.

Tfh cells: As discussed above, substantial progress has been made to selectively target germinal center formation and high affinity antibody production of self-reactive $B$ cells. However, more investigation should be made to curb self-reactive $\mathrm{B}$ cells, while not affecting the overall immune system. Tfh cells are a subset of effector $\mathrm{CD} 4^{+}$ $\mathrm{T}$ cells with specialized functions to help $\mathrm{B}$ cells form germinal centers, and are therefore could be an ideal alternative target to accomplish this therapeutic regimen. This idea is further supported by piling evidence that strongly implies unique differentiation pathways for the generation of Tfh cells (18). Therefore, identification of pathways that are selectively required for $\mathrm{Tfh}$, but not other effector $\mathrm{CD} 4^{+} \mathrm{T}$ cell, differentiation, would be the next step. Here, we discuss animal models of autoimmune disorders, with which relevance of Tfh cell biology have been and will be worth to be tested.

\section{i. Systemic lupus erythematosus}

Systemic lupus erythematosus (SLE), also known simply as lupus, is an autoimmune disease, which is triggered by dysregulated homeostasis of immune system, especially spontaneous activation of $\mathrm{B}$ cells and $\mathrm{T}$ cells. While multiple risk factors are believed to trigger the activation of $\mathrm{B}$ cells and $\mathrm{T}$ cells, autoantibodies against self-antigens, such as anti-double stranded (ds) DNA antibodies and ANA, are responsible for destruction of our body's own tissues through the formation of immune-complexes. CD38-expressing Ig-secreting cells are present in active lupus patients, which are not present in healthy individuals (34), indicating autoantibody production is produced through robust formation of germinal centers in lupus patients. Various mouse models exhibiting similar immunopathologies to human lupus were developed and have been under thorough investigation to better reveal what causes aberrant spontaneous activation of immune system leading to the massive production of autoantibodies.

Sanroque. Sanroque mice were developed by ENU mutagenesis, which introduced a point mutation in Roquin-1 gene (also known as Rc3h1) that encodes RING-type ubiquitin ligase (45). This enzyme plays important roles in post-transcriptional regulation of gene expression by leading to degradation of mRNAs through binding to a constitutive decay element (CDE) in target gene mRNA (46). Sanroque mice were reported originally to develop lupus-like autoimmune disorders due to a loss of function in Roquin-1 gene, resulting in dysregulated expression of target genes, including Icos. A recent study identified that Sanroque mice develop systemic autoimmune pathologies through a gain of function mutation in Roquin- 1 gene, as $\mathrm{CD}^{+} \mathrm{T}$ cell specific Roquin-1 knockout mice did not recapitulate autoimmune phenotypes of Sanroque mice (47). Nonetheless, inducible T cell co-stimulator (ICOS), encoded by Icos, is one of the most critical molecules for Tfh differentiation $(48,49)$. As such, abnormal high expression of ICOS by $\mathrm{CD}^{+} \mathrm{T}$ cells was reported to induce spontaneous formation of germinal centers, which ultimately led to high affinity autoantibody production. While abnormal Tfh differentiation resulting from dysregulated ICOS expression contributes to autoimmune phenotypes in Sanroque mice, Icos-deficiency did not completely reverse the autoimmune phenotypes of Sanroque mice, as splenomegaly was observed in $I \cos ^{-/-}$Roquin $^{\text {san/san }}$ 
mice (50), implying that dysregulation of Icos expression may not be the only trigger for autoimmune disorders of Sanroque mice.

BXSB.Yaa. Like Sanroque mice, BXSB. Yaa mice develop lupus-like immune pathologies mostly due to aberrant activation of self-reactive B cells that harbor duplicate Tlr7 gene on the Y chromosome of SB/Le male mice (51). These B cells, which otherwise would not get activated in response to self-RNA antigens, can be hyper-responsive to RNA antigens due to the presence of extra copy of Tlr7 gene and produce high-affinity autoantibodies. These processes appear to occur in IL21 dependent manners, as BXSB.Yaa mice deficient in IL-21 receptor do not develop autoimmune phenotypes (52). While Tfh cells are not the only effector $\mathrm{CD}^{+} \mathrm{T}$ cells that produce IL-21 (53), BXSB.Yaa mice could serve a good animal model to further dissect pathogenic roles of IL-21 mediated autoantibody production in lupus as IL-21 production of Tfh cells is critical to support Bcl6 expression of germinal center B cells to undergo continuous proliferation (54) as well as to enhance antibody production through induction of Blimp1 in antibody secreting B cells (55).

$M_{R} L^{\text {lpr }}$. MRL ${ }^{\text {lpr }}$ mice were established by insertion of lpr locus (now known as Fas gene) into MRL mouse strain. Defects in Fas expression lead to lupus-like autoimmune phenotypes of MRL ${ }^{\mathrm{lpr}}$ mice including lymphadenopathy, massive production of autoantibodies, and immune complex mediated glomerulonephritis (56). In a stark contrast to Sanroque mice, which the onset of autoimmune phenotypes results from the generation of high affinity antibody producing cells in germinal centers, $M L^{\text {lpr }}$ mice develop autoimmune pathologies due mostly to class-switched and affinity matured antibody secreting plasma cells that develop from extrafollicular foci at the border of T cell zone and B cell follicles (57). Craft and colleagues revealed that $\mathrm{CD}^{+} \mathrm{T}$ cells that express low level of PSGL-1 (P-selectin glyroprotein ligand-1) are responsible for autoantibody production outside $\mathrm{B}$ cell follicles in CD40L- and IL-21-dependent manners (58). Since Tfh cells are major population to downregulate PSGL-1 expression among activated CD4 ${ }^{+} \mathrm{T}$ cells (59), further studies may be able to further dissect whether dysregulated $\mathrm{Tfh}$ differentiation or localization might be associated with perturbed immune responses of MRL ${ }^{1 p r}$ mice.

NZB/W F1. NZB/W F1 hybrid is the first mouse model established to study pathophysiology of human lupus as these mice spontaneously develop systemic autoimmune disorders including splenomegaly, spontaneous germinal center formation, autoantibody production, and exhibit severe renal disease, typical clinical features of human lupus patients (60). While NZB/W F1 mice exhibit different requirement of IFN- $\gamma$ in the course of disease progression from MRL ${ }^{1 p r}$ mice $(61,62), \mathrm{PSGL}^{\mathrm{lo}} \mathrm{CD}^{+}$ $\mathrm{T}$ cells, which contribute to high affinity autoantibody production outside germinal centers $(58,59)$, were strongly expanded in NZB/W F1 mouse spleens in an age-dependent manner (58), implying that there could be a common, but IFN- $\gamma$ independent, factor leading to the differentiation of PSGL- $1{ }^{\text {lo }} \mathrm{CD}^{+} \mathrm{T}$ cells to elicit unfavorable extrafollicular antibody responses. As such, further investigation on the Tfh differentiation of MRL ${ }^{\mathrm{lpr}}$ and NZB/W F1 mice would provide mechanistic insights into IFN- $\gamma$ dependent and IFN- $\gamma$ independent pathways that contribute to the onset of autoimmune pathologies in lupus.

BXD2. BXD2 mice, one of about 80 BXD recombinant inbred mouse strains produced by cross between C57BL/6J and DBA/2J mice, develop spontaneously erosive arthritis and glomerulonephritis (63), and are therefore serve as an animal model for lupus as well as rheumatoid arthritis (RA). A genetic linkage analysis study revealed that the serum levels of anti-DNA antibodies and rheumatoid factor (RF, discussed below) of BXD2 mice were influenced by genetic loci on chromosome 2 and 4, respectively, next to loci associated with B cell hyperactivity and glomerulonephritis susceptibility (63). Chung and colleagues demonstrated that the PD $1^{+} \mathrm{CXCR}^{+}$Tfh cells induced germinal center formation and production of anti-DNA autoantibodies in IL-21 dependent manners in BXD2 mice (64). Moreover, IL-21 functions to further worsen autoimmune pathologies of BXD2 mice, as IL-21 increased the ratio of Tfh cells to Tfr (follicular regulatory T) cells, which inhibit Tfhmediated germinal center formation, by inhibiting Tfr cell development (65). Taken together, BXD2 mice will be a good model to examine pathogenesis and pathophysiology of IL-21 production of Tfh cells in the development of lupus as well as RA.

\section{ii. Rheumatoid arthritis}

Rheumatoid arthritis (RA) is another type of systemic autoimmune diseases and is characterized by symmetric joint swelling and pain, which eventually contributes to bone erosion and joint deformity (66). The exact pathogenesis of RA is largely unknown; however, both genetic and environmental factors are believed to trigger RA. Among multiple genetic risk factors, human leukocyte antigen (HLA)-DRB1 gene is the major genetic susceptibility locus (67), indicating that a fraction of HLA class II recognizing $\mathrm{CD}^{+} \mathrm{T}$ cells might be directly involved with the onset of rheumatoid arthritis. While 
it is not clear whether these arthritogenic $\mathrm{CD}^{+} \mathrm{T}$ cells, which are prone to induce arthritis, might be clearly associated with autoantibody production in RA patients, autoantibodies, such as rheumatoid factor (anti-IgG Fc fragment) and anti-citrullinated peptide antibody (ACPA), are found in $50 \sim 80 \%$ of RA patients (66). Of note, increased frequency of $\mathrm{PD} 1{ }^{\text {hi }} \mathrm{CXCR} 5^{+}$circulating Tfh-like cells was detected in the peripheral blood of RA patients with concomitant increase of IL-21 level in serum (68). As such, Tfh cells seem to be strongly associated with the pathogenesis and pathophysiology of RA, and have been thorough investigation using mouse models listed below.

$\mathbf{K} / \mathbf{B} \mathbf{X N}$. K/BxN mice were generated by crossing mice that express KRN T cell receptor (TCR) transgene with mice such as non-obese diabetic (NOD) mice, whose MHC II haplotype is I-A ${ }^{\mathrm{g} 7}(69)$. These mice develop severe inflammation and autoimmune phenotypes in clinically similar ways to human RA (70). Spontaneous germinal center formation of self-reactive $\mathrm{B}$ cells and autoantibody production, components responsible for the pathogenesis of $\mathrm{RA}$ in $\mathrm{K} / \mathrm{BxN}$ mice, occur in $\mathrm{Tfh}$ cell dependent manners $(71,72) . \mathrm{K} / \mathrm{BxN}$ mice do not develop RA when B cells are deficient in CD40 receptor or IL-21 receptor, whose signaling ligands are provided predominantly by Tfh cells for formation of germinal centers $(70,71,73)$. Th17 cells also produce IL-21 and are associated with triggering immune pathologies in autoimmune disorders including rheumatoid arthritis (74,75). However, Th17 cells do not appear to contribute to the pathogenesis of $\mathrm{RA}$ at least in $\mathrm{K} / \mathrm{BxN}$ mice, as $\mathrm{RA}$ did not develop in $\mathrm{K} / \mathrm{BxN}$ mice deficient in $\mathrm{B}$ cells (70), which are not critical for Th17 cell differentiation. Nonetheless, autoantibody-mediated immune destruction appears to get worse in the presence of IL-17 producing cells (76), indicating immunological functions of Th17 cells could modulate the progression of the disease, while Th17 cells by themselves are not capable of eliciting autoimmune pathologies in RA.

SKG. While K/BxN mice serve as an ideal model of RA, the pathophysiology of $\mathrm{K} / \mathrm{BxN}$ mice is predominantly dependent on anti-glucose-6-phosphate isomerase (GPI) antibody (77), whereas rheumatoid factor (RF) or ACPA is not observed in $\mathrm{K} / \mathrm{BxN}$ mice. SKG mice were developed by introducing a point mutation on Zap70, a gene encoding ZAP70 that is a critical signaling molecule in $\mathrm{T}$ cells (78). SKG mice develop chronic inflammation spontaneously and exhibit clinical signs of human RA patients, including the production of rheumatoid factor as well as anti-type II collagen specific autoantibodies (78). However, by a sharp contrast to $\mathrm{K} / \mathrm{BxN}$ mice, adoptive transfer of $\mathrm{T}$ cells, but not serum or B cells, of SKG mice led to the development of RA in T cell-deficient athymic BALB/c nude mice (78), strongly indicating the pathogenesis of RA in SKG mice is predominantly induced by $\mathrm{T}$ cells, but not through immune complex formation of autoantibodies. Taken together, while rheumatoid factor is present in SKG mice, this mouse strain may be a better model to study the pathogenesis of RA in the context of non-Tfh cell compartments.

CIA. Collagen-induced arthritis (CIA) is induced by immunization of type II collagen, the major protein in cartilage, emulsified in Complete Freund's Adjuvant. Both $\mathrm{B}$ and $\mathrm{T}$ cells elicit strong immune responses, which contribute to synovial hyperplasia, mononuclear cell infiltration, and cartilage degradation (79). Strong anti-type II collagen antibody responses are induced by CIA immunization, while rheumatoid factor is not detected in immunized mice (79). Most interestingly, like RA pathogenesis in human, RA is inducible by CIA immunization in a limited strain of mice in MHC II haplotype dependent manners, with DBA/1 mice (H$2^{q}$ ) as the gold standard strain (79). Because transgenic or gene knock-in or knock-out lines are not readily available in DBA/1 mouse strain, mechanistic studies can be performed when reagents that block signaling molecules of interest are available. Nonetheless, Zhang and colleagues revealed that immunological functions of Tfh cells are required for the progression of RA (80). A blockade antibody against ICOS-L (B7RP-1), which blocks cognate interaction between Tfh cells and germinal center B cells (48), resulted in reductions in Tfh cell numbers and germinal center reactions, which ultimately ameliorated overall disease index in DBA/1 mice (80).

\section{iii. Multiple sclerosis}

Multiple sclerosis (MS) is a chronic, inflammatory and neurodegenerative autoimmune disorder, which is caused by destruction of myelin antigens in the central nervous system (CNS) including myelin basic protein (MBP), proteolipidprotein (PLP), and myelin oligodendrocyte glycoprotein (MOG) (81). The pathogenicity of MS is highly associated with HLA class II haplotypes like that of RA in human; therefore, it is believed that abnormal activation of $\mathrm{CD} 4^{+} \mathrm{T}$ cells might be a pathophysiological trigger for MS in human (82). This idea is supported by studies that revealed the concentration of IFN- $\gamma$ and IL17A and IL-17F, the Th1 and Th17 cell cytokines, was higher in peripheral blood and cerebrospinal fluid (CSF) of MS patients than healthy subjects (83). While $\mathrm{CD}^{+} \mathrm{T}$ cells appear to be responsible for the onset of the disease, autoantibodies were recently suggested to contribute to 
the disease course. Not only are antibodies against myelin antigen present in blood and CSF of MS patients (84), adoptive transfer of human anti-MOG antibodies but also resulted in enhanced demyelination of the CNS in a mouse model of MS (85). These studies suggest that antibody production of B cells should be also considered as a therapeutic target to cure MS. Interestingly, IL21-producing $\mathrm{CD}^{+} \mathrm{T}$ cells were identified among MS lesion infiltrating cells (86). While Tfh cells are not the only IL21 producing CD4 $4^{+} \mathrm{T}$ cells, potential pathophysiological roles of Tfh cells will be worth to be examined in mouse models of MS.

$\boldsymbol{E A E}$. Experimental autoimmune encephalomyelitis (EAE) is an animal model of inflammation in the CNS, and is the most common model to study pathogenesis and pathophysiology of human MS. It is triggered by immunizing experimental animals with myelin antigens emulsified in adjuvants leading to the generation of encephalitogenic myelin antigen specific Th1 or Th17 cells $(83,87)$. Depending on dose of antigens during immunization and genetic susceptibility of the animals, EAE could develop in either acute monophasic, a remitting-relapsing, or chronic forms (88). While EAE model has not been explored in the context of immunological functions of Tfh cells (i.e., examination of EAE development in $\mathrm{CD}^{+} \mathrm{T}$ cell specific Bcl6 KO mice or other mouse strains where Tfh cell differentiation is inhibited), the identification of ectopic lymphoid follicles (ELFs) inside the CNS of both MS patients and EAE mouse strongly suggest that germinal centers once formed in the ELFs in the presence of Tfh cells could contribute to exacerbate disease progress $(89,90)$. Secondary progressive MS (SPMS) comes after relapsing and remitting MS in many cases (91). Of note, myelin antigen specific antibody responses are strongly associated with SPMS and ELFs are found in more than $40 \%$ of SPMS patients (92). Thus, future studies are necessary to address whether Tfh differentiation or functions could be targeted to ameliorate the disease progression of MS.

hHLA-tg mice. As discussed above, HLA class II haplotype is strongly associated with the pathophysiology of MS. Serological HLA typing and DNA sequencing analysis revealed that HLA-DR15 haplotype, which encodes three types of HLA class II heterodimers (DR15 [DRA1*0101/ DRB1*1501], DRB5 [DRA1*0101/DRB5*0101], and DQ6 [DQA1*0102/DQB1*0602]), is the most prevalent type among MS patients of North European Caucasian origin (82). DRB1*1501 was suggested as the major risk factor leading to increased susceptibility to MS (93). However, due to a strong linkage disequilibrium between
HLA-DR and HLA-DQ alleles (93), more precise systems are necessary to address whether HLA-DR allele or HLA-DQ allele, or both, functions as the primary risk factor during onset and progress of the disease. Mouse models with human HLA transgenes were established and are available to examine the pathophysiology of MS in response to immunization with myelin antigens, such as human PLP and myelin-associated oligodendrocytic basic protein (MOBP). Previous works with mice with HLA-DR15 (DRA1*0101/DRB1*1501) and HLA-DQ6 (DQA $1 * 0102 / \mathrm{DQB} 1 * 0602)$ transgenes revealed HLADQB $1 * 0602$ confers susceptibility to the development of MS $(94,95)$. These mice might be useful tools to understand whether, and how if so, Tfh cells could contribute to the production of myelin-specific autoantibodies in antigen specific ways during the onset or the course of MS.

\section{iv. Myasthenia gravis}

Myasthenia gravis (MG) is an uncommon disorder caused by fluctuating muscle weakness, which develops in congenital or acquired forms (96). While the former is attributed to the loss of function mutations on AChR (a gene encoding acetylcholine receptor) (97), dysregulated immune responses, especially the production of autoantibodies against AChR, are responsible for the onset of acquired form of MG (96). A recent study suggested that Tfh cells may function upstream of anti-AChR antibodies as the percentage of circulating Tfh cells was strongly correlated with the levels of anti-AChR antibodies in MG patients (98).

EAMG. Experimental autoimmune myasthenia gravis (EAMG) is the mouse model for MG (99). MG could be elicited by immunizing mice with AChR extracted from Torpedo californica or electric ray (100). Previous works demonstrated that EAMG mouse model serves as a good tool to explore therapeutic targets to cure the acquired form of MG (99). A recent study revealed that AChR immunization led to expansion of Tfh cells in spleen, which was strongly correlated with autoantibody production. Systemic delivery of lentivirus that express small interference RNA (siRNA) against Bcl6 reversed MG phenotypes of EAMG mice (101), suggesting that Tfh cells would be an ideal therapeutic target. Given that Bcl6 is critical for maintenance of germinal center B cells, it remains to be elucidated whether siRNA against Bcl6 directly targeted Tfh cells, or the reversion of MG phenotypes was due to a failure of germinal center B cells to sustain germinal center reaction. Nonetheless, these studies indicate that future studies should focus to target $\mathrm{Tfh}$ cells by themselves or their function to maintain germinal center reactions. 


\section{v. Sjogren's syndrome}

Sjogren's syndrome (SS) is a chronic inflammatory autoimmune disease characterized by progressive damage to the exocrine glands, such as salivary and lacrimal glands, due partly to leukocytic infiltration (102). Like other autoimmune disorders, both genetic and environmental factors contribute to the pathogenesis of SS $(103,104)$. Depending on whether it affects exocrine glands only or includes systemic tissues, SS is classified into primary (pSS) and secondary (sSS), respectively (105). Several types of autoantibodies, including rheumatoid factor (RF), anti-nuclear antibody (ANA), anti-SSA/Ro and anti-SSB/La (106), are present in serum of SS patients, implying that the onset and progression of the disease results, at least in part, from high affinity antibody production against self-antigens. As such, Tfh cells could be therapeutic targets. In recent studies with patients suffering from pSS, CXCR5 expressing $\mathrm{CD} 4^{+} \mathrm{T}$ cells were found at much higher frequencies in both salivary gland and peripheral blood of pSS patients $(107,108)$. Also, the increase in Tfh cell numbers in pSS patients was strongly correlated with the frequencies of $\mathrm{CD} 19^{+} \mathrm{CD} 27^{+}$ memory B cells and $\mathrm{CD} 19^{+} \mathrm{CD} 27^{\text {hi }}$ plasma cells and the level of serum ANA titer, strongly implying that $\mathrm{Tfh}$ cells should be targeted for the development of novel therapeutic interventions of SS.

While various mouse models have been established to study the pathogenesis of SS and pathophysiological understanding of immune cells in SS, and were recently reviewed elsewhere (109), there is not much work done to specifically address Tfh biology in the context of the onset and disease progression of pSS and sSS. Among molecules examined as therapeutic targets of SS, TACI, CD40 and CXCL13 are associated with differentiation or immunological functions of Tfh cells (109). Hence, future studies need to further dissect the modes of actions of these molecules in the regulation of Tfh cells during the course of the disease.

\section{Tfh cells as new targets of immunosuppression in allograft}

The immune system recognizes allografts as foreign, and therefore does their jobs to destroy non-self organs or tissues following transplantation, as educated. Among immune cells, T cells have been recognized as the major player in allograft rejection, as it was reported more than 40 years ago that athymic nude mice accepted skin grafts originated from distant mammals (humans), birds, reptiles, amphibians, and so on (110). Thanks to recent progress in immunosuppressive strategies targeting $\mathrm{T}$ cells, short-term graft survival rates have been substantially improved following allografts of kidney or the heart (111). However, long-term allografts frequently succumb to chronic rejection, which is hardly controlled by immunosuppressive drugs due to increasing susceptibility to infections if given for a long time. Moreover, there are still acute rejections occurring after organ transplantation even in the presence of $\mathrm{T}$ cell targeting drugs (112), indicating that non $\mathrm{T}$ cell immune compartments should participate in allograft rejections and must be considered for development of therapeutic interventions.

Following transplantation, B cells produce donor-specific antibodies (DSA) predominantly against HLA class I haplotypes expressed by endothelial cells of allografts. Anti-HLA class I antibodies were shown to participate in acute rejection through formation of membrane attack complexes (MAC) and also to play roles in chronic rejection by inducing endothelial cell activation $(113,114)$. While high levels of DSA are frequently found in recipients who rejected allografts, it is not clear whether DSA could be used a biomarker for allograft rejection as (i) not all DSA positive recipients reject allografts and (ii) DSA are frequently found present in recipients even before allograft transplantation (113). Thus, the roles of B cells have remained enigmatic until recently when inhibition of alloantibody production of B cells led to prolonged survival of allograft survival (115). Multiple studies with mouse models reported that blockade antibodies against $\mathrm{B}$ cell activating factor (BAFF), a proliferation inducing ligand (APRIL), or IFN $-\gamma$ abrogated B cell help of memory $\mathrm{CD}^{+} \mathrm{T}$ cells, and contribute to prolong allograft survival through suppression of DSA $(116,117)$.

In a recent study with renal allograft recipients, donor HLA class I specific antibody producing B cells were found present in blood only after transplantation (118), strongly implying that antigen-specific adaptive B cell responses could develop in response to allografts. Baan and colleagues examined the kidney biopsies that were obtained from recipients with ongoing renal allograft failure and found that Tfh cells and B cells co-localized (119), indicating Tfh cells could trigger alloantigenspecific antibody production by B cells. Using a mouse model of allogeneic hematopoietic stem cell transplantation, Blazar and colleagues revealed that $\mathrm{Tfh}$ cells are required for chronic graft-versus-host disease (cGVHD) in mice (120). Taken together, these studies indicate that $\mathrm{Tfh}$ cells are additional targets to consider for improving immunosuppressive drugs for prolonged allograft survival. 


\section{DISCUSSION}

Immune system should be kept in control as dysregulated or undesirable immune responses introduce big hurdles in autoimmune diseases and allograft rejection. Multiple genetic and environmental factors are operational during these deleterious immune functions. Many efforts have been made to develop strategies for intervening immune responses that are associated with pathogenesis and pathophysiology of autoimmune disorders and transplant rejection. However, the vast majority of therapeutic interventions aim the entire immune system, while little is available to selectively modulate ones that cause harmful effects. Immunosupressive strategies frequently shut the entire $\mathrm{T}$ cell responses off, which are very likely to increase susceptibilities of the host to bacterial, fungal, parasitic, and viral infections due to the failure of $\mathrm{CD}_{4}^{+}$ $\mathrm{T}$ cells to form Th1 (viral and bacterial infection), Th2 (helminth infection), or Th17 (fungal and bacterial infection) cells. Therefore, specific targets should be discovered to practically control autoimmune disorders and allograft rejection. Spontaneous germinal center formation and high affinity antibody production against self-antigens or alloantigens are highly associated with the onset and disease progression of dysregulated autoimmune disorders and undesirable rejection responses to allografts. As germinal centers develop in Tfh cell dependent manners, Tfh cells are recognized as new therapeutic targets. As discusses in this review paper, studies using animal models of autoimmune disorders and transplant rejection as well as with human patients revealed biological relevance of Tfh cells to the pathogenesis and pathophysiology of autoimmune diseases and allograft rejections. Future studies will focus to elucidate signaling molecules and/ or signaling pathways to selectively inhibit differentiation and immunological functions of Tfh cells, which will provide mechanistic insights for development of novel therapeutic interventions for autoimmune diseases and allograft rejection.

\section{ACKNOWLEDGEMENTS}

This work was supported by Research Resettlement Fund for the new faculty of Seoul National University (to YSC) and research grants SNU invitation program for distinguished scholar (to YSC) and SNUH Research Fund (03-2016-0060) (to YSC).

\section{REFERENCES}

1. Murphy, K. 2012. Janeway's Immunobiology. Garland Science. 8th ed.

2. Kyewski, B., and L. Klein. 2006. A central role for central tolerance. Annu. Rev. Immunol. 24: 571-606.

3. Hardy, R. R., and K. Hayakawa. 2001. B cell development pathways. Annu. Rev. Immunol. 19: 595-621.

4. Sandel, P. C., and J. G. Monroe. 1999. Negative selection of immature $\mathrm{B}$ cells by receptor editing or deletion is determined by site of antigen encounter. Immunity 10: 289-299.

5. Goodnow, C. C., S. Adelstein, and A. Basten. 1990. The need for central and peripheral tolerance in the B cell repertoire. Science 248: 1373-1379.

6. Lim, P. L., and M. Zouali. 2006. Pathogenic autoantibodies: emerging insights into tissue injury. Immunol. Lett. 103: 1726.

7. Baumgarth, N., Y. S. Choi, K. Rothaeusler, Y. Yang, and L. A. Herzenberg. 2008. B cell lineage contributions to antiviral host responses. Curr. Top. Microbiol. Immunol. 319: 41-61.

8. Baumgarth, N. 2013. Innate-like B cells and their rules of engagement. Adv. Exp. Med. Biol. 785: 57-66.

9. Cerutti, A., M. Cols, and I. Puga. 2013. Marginal zone B cells: virtues of innate-like antibody-producing lymphocytes. Nat. Rev. Immunol. 13: 118-132.

10. Victora, G. D., and M. C. Nussenzweig. 2012. Germinal centers. Annu. Rev. Immunol. 30: 429-457.

11. Zhu, J., H. Yamane, and W. E. Paul. 2010. Differentiation of effector CD4 T cell populations (*). Annu. Rev. Immunol. 28: 445-489.

12. Crotty, S. 2011. Follicular helper CD4 T cells (TFH). Annu. Rev. Immunol. 29: 621-663.

13. Johnston, R. J., A. C. Poholek, D. DiToro, I. Yusuf, D. Eto, B. Barnett, A. L. Dent, J. Craft, and S. Crotty. 2009. Bcl6 and Blimp-1 are reciprocal and antagonistic regulators of T follicular helper cell differentiation. Science 325: 1006-1010.

14. Nurieva, R. I., Y. Chung, G. J. Martinez, X. O. Yang, S. Tanaka, T. D. Matskevitch, Y. H. Wang, and C. Dong. 2009. Bcl6 mediates the development of T follicular helper cells. Science 325: 1001-1005.

15. Yu, D., S. Rao, L. M. Tsai, S. K. Lee, Y. He, E. L. Sutcliffe, M. Srivastava, M. Linterman, L. Zheng, N. Simpson, J. I. Ellyard, I. A. Parish, C. S. Ma, Q. J. Li, C. R. Parish, C. R. Mackay, and C. G. Vinuesa. 2009. The transcriptional repressor Bcl-6 directs $\mathrm{T}$ follicular helper cell lineage commitment. Immunity 31: 457-468.

16. Baumjohann, D., S. Preite, A. Reboldi, F. Ronchi, K. M. Ansel, A. Lanzavecchia, and F. Sallusto. 2013. Persistent antigen and germinal center B cells sustain $\mathrm{T}$ follicular helper cell responses and phenotype. Immunity 38: 596-605. 
17. Ballesteros-Tato, A., B. Leon, B. A. Graf, A. Moquin, P. S. Adams, F. E. Lund, and T. D. Randall. 2012. Interleukin-2 inhibits germinal center formation by limiting $\mathrm{T}$ follicular helper cell differentiation. Immunity 36: 847-856.

18. Vinuesa, C. G., M. A. Linterman, D. Yu, and I. C. MacLennan. 2016. Follicular Helper T Cells. Annu. Rev. Immunol. 34: 335-368.

19. Plotkin, S. A. 2008. Vaccines: correlates of vaccine-induced immunity. Clin. Infect. Dis. 47: 401-409.

20. Sherer, Y., A. Gorstein, M. J. Fritzler, and Y. Shoenfeld. 2004. Autoantibody explosion in systemic lupus erythematosus: more than 100 different antibodies found in SLE patients. Semin. Arthritis Rheum. 34: 501-537.

21. Basso, K., C. Schneider, Q. Shen, A. B. Holmes, M. Setty, C. Leslie, and R. la-Favera. 2012. BCL6 positively regulates AID and germinal center gene expression via repression of miR-155. J. Exp. Med. 209: 2455-2465.

22. Kosco-Vilbois, M. H. 2003. Are follicular dendritic cells really good for nothing? Nat. Rev. Immunol. 3: 764-769.

23. MacLennan, I. C. 1994. Germinal centers. Annu. Rev. Immunol. 12: 117-139.

24. Romagnani, S. 2000. T-cell subsets (Th1 versus Th2). Ann. Allergy Asthma Immunol. 85: 9-18.

25. Andoh, A., A. Masuda, M. Yamakawa, Y. Kumazawa, and T. Kasajima. 2000. Absence of interleukin-4 enhances germinal center reaction in secondary immune response. Immunol. Lett. 73: 35-41.

26. Schaerli, P., K. Willimann, A. B. Lang, M. Lipp, P. Loetscher, and B. Moser. 2000. CXC chemokine receptor 5 expression defines follicular homing T cells with B cell helper function. $J$. Exp. Med. 192: 1553-1562.

27. Chtanova, T., S. G. Tangye, R. Newton, N. Frank, M. R. Hodge, M. S. Rolph, and C. R. Mackay. 2004. T follicular helper cells express a distinctive transcriptional profile, reflecting their role as non-Th1/Th2 effector cells that provide help for B cells. J. Immunol. 173: 68-78.

28. Kim, C. H., H. W. Lim, J. R. Kim, L. Rott, P. Hillsamer, and E. C. Butcher. 2004. Unique gene expression program of human germinal center T helper cells. Blood 104: 1952-1960.

29. Rasheed, A. U., H. P. Rahn, F. Sallusto, M. Lipp, and G. Muller. 2006. Follicular B helper T cell activity is confined to CXCR5(hi)ICOS(hi) CD4 T cells and is independent of CD57 expression. Eur. J. Immunol. 36: 1892-1903.

30. Kroenke, M. A., D. Eto, M. Locci, M. Cho, T. Davidson, E. K. Haddad, and S. Crotty. 2012. Bcl6 and Maf cooperate to instruct human follicular helper CD4 T cell differentiation. $J$. Immunol. 188: 3734-3744.

31. Achenbach, P., K. Koczwara, A. Knopff, H. Naserke, A. G. Ziegler, and E. Bonifacio. 2004. Mature high-affinity immune responses to (pro)insulin anticipate the autoimmune cascade that leads to type 1 diabetes. J. Clin. Invest 114: 589-597.

32. Shlomchik, M., M. Mascelli, H. Shan, M. Z. Radic, D. Pisetsky, A. Marshak-Rothstein, and M. Weigert. 1990. AntiDNA antibodies from autoimmune mice arise by clonal expansion and somatic mutation. J. Exp. Med. 171: 265-292.

33. van Es, J. H., F. H. Gmelig Meyling, W. R. van de Akker, H. Aanstoot, R. H. Derksen, and T. Logtenberg. 1991. Somatic mutations in the variable regions of a human IgG anti-doublestranded DNA autoantibody suggest a role for antigen in the induction of systemic lupus erythematosus. J. Exp. Med. 173: 461-470.

34. Grammer, A. C., R. Slota, R. Fischer, H. Gur, H. Girschick, C. Yarboro, G. G. Illei, and P. E. Lipsky. 2003. Abnormal germinal center reactions in systemic lupus erythematosus demonstrated by blockade of CD154-CD40 interactions. $J$. Clin. Invest 112: 1506-1520.

35. Hoyer, B. F., K. Moser, A. E. Hauser, A. Peddinghaus, C. Voigt, D. Eilat, A. Radbruch, F. Hiepe, and R. A. Manz. 2004. Short-lived plasmablasts and long-lived plasma cells contribute to chronic humoral autoimmunity in NZB/W mice. J. Exp. Med. 199: 1577-1584.

36. Sanchez, M., Z. Misulovin, A. L. Burkhardt, S. Mahajan, T. Costa, R. Franke, J. B. Bolen, and M. Nussenzweig. 1993. Signal transduction by immunoglobulin is mediated through Ig alpha and Ig beta. J. Exp. Med. 178: 1049-1055.

37. Heyman, B. 2000. Regulation of antibody responses via antibodies, complement, and Fc receptors. Annu. Rev. Immunol. 18: 709-737.

38. Pone, E. J., H. Zan, J. Zhang, A. Al-Qahtani, Z. Xu, and P. Casali. 2010. Toll-like receptors and B-cell receptors synergize to induce immunoglobulin class-switch DNA recombination: relevance to microbial antibody responses. Crit. Rev. Immunol. 30: 1-29.

39. Pelanda, R., U. Braun, E. Hobeika, M. C. Nussenzweig, and M. Reth. 2002. B cell progenitors are arrested in maturation but have intact VDJ recombination in the absence of Ig-alpha and Ig-beta. J. Immunol. 169: 865-872.

40. Soni, C., E. B. Wong, P. P. Domeier, T. N. Khan, T. Satoh, S. Akira, and Z. S. Rahman. 2014. B cell-intrinsic TLR7 signaling is essential for the development of spontaneous germinal centers. J. Immunol. 193: 4400-4414.

41. Clingan, J. M., and M. Matloubian. 2013. B Cell-intrinsic TLR7 signaling is required for optimal B cell responses during chronic viral infection. J. Immunol. 191: 810-818.

42. Domeier, P. P., S. B. Chodisetti, C. Soni, S. L. Schell, M. J. Elias, E. B. Wong, T. K. Cooper, D. Kitamura, and Z. S. Rahman. 2016. IFN-gamma receptor and STAT1 signaling in $\mathrm{B}$ cells are central to spontaneous germinal center formation and autoimmunity. J. Exp. Med. 213: 715-732.

43. Cantin, E., B. Tanamachi, H. Openshaw, J. Mann, and K. 
Clarke. 1999. Gamma interferon (IFN-gamma) receptor nullmutant mice are more susceptible to herpes simplex virus type 1 infection than IFN-gamma ligand null-mutant mice. $J$. Virol. 73: 5196-5200.

44. Kjerrulf, M., D. Grdic, L. Ekman, K. Schon, M. Vajdy, and N. Y. Lycke. 1997. Interferon-gamma receptor-deficient mice exhibit impaired gut mucosal immune responses but intact oral tolerance. Immunology 92: 60-68.

45. Vinuesa, C. G., M. C. Cook, C. Angelucci, V. Athanasopoulos, L. Rui, K. M. Hill, D. Yu, H. Domaschenz, B. Whittle, T. Lambe, I. S. Roberts, R. R. Copley, J. I. Bell, R. J. Cornall, and C. C. Goodnow. 2005. A RING-type ubiquitin ligase family member required to repress follicular helper $\mathrm{T}$ cells and autoimmunity. Nature 435: 452-458.

46. Leppek, K., J. Schott, S. Reitter, F. Poetz, M. C. Hammond, and G. Stoecklin. 2013. Roquin promotes constitutive mRNA decay via a conserved class of stem-loop recognition motifs. Cell 153: 869-881.

47. Vogel, K. U., S. L. Edelmann, K. M. Jeltsch, A. Bertossi, K. Heger, G. A. Heinz, J. Zoller, S. C. Warth, K. P. Hoefig, C. Lohs, F. Neff, E. Kremmer, J. Schick, D. Repsilber, A. Geerlof, H. Blum, W. Wurst, M. Heikenwalder, M. SchmidtSupprian, and V. Heissmeyer. 2013. Roquin paralogs 1 and 2 redundantly repress the Icos and Ox40 costimulator mRNAs and control follicular helper $\mathrm{T}$ cell differentiation. Immunity 38: 655-668.

48. Choi, Y. S., R. Kageyama, D. Eto, T. C. Escobar, R. J. Johnston, L. Monticelli, C. Lao, and S. Crotty. 2011. ICOS receptor instructs $\mathrm{T}$ follicular helper cell versus effector cell differentiation via induction of the transcriptional repressor Bc16. Immunity 34: 932-946.

49. Nurieva, R. I., Y. Chung, D. Hwang, X. O. Yang, H. S. Kang, L. Ma, Y. H. Wang, S. S. Watowich, A. M. Jetten, Q. Tian, and C. Dong. 2008. Generation of T follicular helper cells is mediated by interleukin-21 but independent of T helper 1, 2, or 17 cell lineages. Immunity 29: 138-149.

50. Lee, S. K., D. G. Silva, J. L. Martin, A. Pratama, X. Hu, P. P. Chang, G. Walters, and C. G. Vinuesa. 2012. Interferongamma excess leads to pathogenic accumulation of follicular helper T cells and germinal centers. Immunity 37: 880-892.

51. Pisitkun, P., J. A. Deane, M. J. Difilippantonio, T. Tarasenko, A. B. Satterthwaite, and S. Bolland. 2006. Autoreactive B cell responses to RNA-related antigens due to TLR7 gene duplication. Science 312: 1669-1672.

52. Bubier, J. A., T. J. Sproule, O. Foreman, R. Spolski, D. J. Shaffer, H. C. Morse, III, W. J. Leonard, and D. C. Roopenian. 2009. A critical role for IL-21 receptor signaling in the pathogenesis of systemic lupus erythematosus in BXSB-Yaa mice. Proc. Natl. Acad. Sci. U. S. A. 106: 15181523.
53. Wei, L., A. Laurence, K. M. Elias, and J. J. O'Shea. 2007. IL21 is produced by Th17 cells and drives IL-17 production in a STAT3-dependent manner. J. Biol. Chem. 282: 34605-34610.

54. Zotos, D., J. M. Coquet, Y. Zhang, A. Light, K. D'Costa, A. Kallies, L. M. Corcoran, D. I. Godfrey, K. M. Toellner, M. J. Smyth, S. L. Nutt, and D. M. Tarlinton. 2010. IL-21 regulates germinal center B cell differentiation and proliferation through a B cell-intrinsic mechanism. J. Exp. Med. 207: 365378.

55. Ozaki, K., R. Spolski, C. G. Feng, C. F. Qi, J. Cheng, A. Sher, H. C. Morse, III, C. Liu, P. L. Schwartzberg, and W. J. Leonard. 2002. A critical role for IL-21 in regulating immunoglobulin production. Science 298: 1630-1634.

56. Watanabe-Fukunaga, R., C. I. Brannan, N. G. Copeland, N. A. Jenkins, and S. Nagata. 1992. Lymphoproliferation disorder in mice explained by defects in Fas antigen that mediates apoptosis. Nature 356: 314-317.

57. Jacobson, B. A., D. J. Panka, K. A. Nguyen, J. Erikson, A. K. Abbas, and A. Marshak-Rothstein. 1995. Anatomy of autoantibody production: dominant localization of antibodyproducing cells to $\mathrm{T}$ cell zones in Fas-deficient mice. Immunity 3: 509-519.

58. Odegard, J. M., B. R. Marks, L. D. DiPlacido, A. C. Poholek, D. H. Kono, C. Dong, R. A. Flavell, and J. Craft. 2008. ICOSdependent extrafollicular helper T cells elicit IgG production via IL-21 in systemic autoimmunity. J. Exp. Med. 205: 28732886.

59. Poholek, A. C., K. Hansen, S. G. Hernandez, D. Eto, A. Chandele, J. S. Weinstein, X. Dong, J. M. Odegard, S. M. Kaech, A. L. Dent, S. Crotty, and J. Craft. 2010. In vivo regulation of Bcl6 and T follicular helper cell development. $J$. Immunol. 185: 313-326.

60. Helyer, B. J., and J. B. Howie. 1963. Renal disease associated with positive lupus erythematosus tests in a cross-bred strain of mice. Nature 197: 197.

61. Jacob, C. O., P. H. van der Meide, and H. O. McDevitt. 1987. In vivo treatment of (NZB X NZW)F1 lupus-like nephritis with monoclonal antibody to gamma interferon. J. Exp. Med. 166: 798-803.

62. Nicoletti, F., P. Meroni, M. R. Di, W. Barcellini, M. O. Borghi, M. Gariglio, A. Mattina, S. Grasso, and S. Landolfo. 1992. In vivo treatment with a monoclonal antibody to interferongamma neither affects the survival nor the incidence of lupusnephritis in the MRL/lpr-lpr mouse. Immunopharmacology 24: 11-16.

63. Mountz, J. D., P. Yang, Q. Wu, J. Zhou, A. Tousson, A. Fitzgerald, J. Allen, X. Wang, S. Cartner, W. E. Grizzle, N. Yi, L. Lu, R. W. Williams, and H. C. Hsu. 2005. Genetic segregation of spontaneous erosive arthritis and generalized autoimmune disease in the BXD2 recombinant inbred strain 
of mice. Scand. J. Immunol. 61: 128-138.

64. Kim, Y. U., H. Lim, H. E. Jung, R. A. Wetsel, and Y. Chung. 2015. Regulation of autoimmune germinal center reactions in lupus-prone BXD2 mice by follicular helper T cells. PLoS One 10: e0120294.

65. Ding, Y., J. Li, P. Yang, B. Luo, Q. Wu, A. J. Zajac, O. Wildner, H. C. Hsu, and J. D. Mountz. 2014. Interleukin-21 promotes germinal center reaction by skewing the follicular regulatory $\mathrm{T}$ cell to follicular helper $\mathrm{T}$ cell balance in autoimmune BXD2 mice. Arthritis Rheumatol. 66: 26012612.

66. Scott, D. L., F. Wolfe, and T. W. Huizinga. 2010. Rheumatoid arthritis. Lancet 376: 1094-1108.

67. Weyand, C. M., K. C. Hicok, D. L. Conn, and J. J. Goronzy. 1992. The influence of HLA-DRB1 genes on disease severity in rheumatoid arthritis. Ann. Intern. Med. 117: 801-806.

68. Liu, R., Q. Wu, D. Su, N. Che, H. Chen, L. Geng, J. Chen, W. Chen, X. Li, and L. Sun. 2012. A regulatory effect of IL21 on $\mathrm{T}$ follicular helper-like cell and B cell in rheumatoid arthritis. Arthritis Res. Ther. 14: R255.

69. Monach, P. A., D. Mathis, and C. Benoist. 2008. The K/BxN arthritis model. Curr. Protoc. Immunol. Chapter 15: Unit 15.22 .

70. Korganow, A. S., H. Ji, S. Mangialaio, V. Duchatelle, R. Pelanda, T. Martin, C. Degott, H. Kikutani, K. Rajewsky, J. L. Pasquali, C. Benoist, and D. Mathis. 1999. From systemic T cell self-reactivity to organ-specific autoimmune disease via immunoglobulins. Immunity 10: 451-461.

71. Block, K. E., and H. Huang. 2013. The cellular source and target of IL-21 in K/BxN autoimmune arthritis. J. Immunol. 191: 2948-2955.

72. Chaiamnuay, S., and S. L. Bridges, Jr. 2005. The role of $\mathrm{B}$ cells and autoantibodies in rheumatoid arthritis. Pathophysiology 12: 203-216.

73. Kyburz, D., D. A. Carson, and M. Corr. 2000. The role of CD40 ligand and tumor necrosis factor alpha signaling in the transgenic K/BxN mouse model of rheumatoid arthritis. Arthritis Rheum. 43: 2571-2577.

74. Eisenstein, E. M., and C. B. Williams. 2009. The T(reg)/Th17 cell balance: a new paradigm for autoimmunity. Pediatr. Res. 65: 26R-31R.

75. Leipe, J., M. Grunke, C. Dechant, C. Reindl, U. Kerzendorf, H. Schulze-Koops, and A. Skapenko. 2010. Role of Th17 cells in human autoimmune arthritis. Arthritis Rheum. 62: 2876-2885.

76. Jacobs, J. P., H. J. Wu, C. Benoist, and D. Mathis. 2009. IL17-producing T cells can augment autoantibody-induced arthritis. Proc. Natl. Acad. Sci. U. S. A. 106: 21789-21794.

77. Maccioni, M., G. Zeder-Lutz, H. Huang, C. Ebel, P. Gerber, J. Hergueux, P. Marchal, V. Duchatelle, C. Degott, R. M. van,
C. Benoist, and D. Mathis. 2002. Arthritogenic monoclonal antibodies from K/BxN mice. J. Exp. Med. 195: 1071-1077.

78. Sakaguchi, N., T. Takahashi, H. Hata, T. Nomura, T. Tagami, S. Yamazaki, T. Sakihama, T. Matsutani, I. Negishi, S. Nakatsuru, and S. Sakaguchi. 2003. Altered thymic T-cell selection due to a mutation of the ZAP-70 gene causes autoimmune arthritis in mice. Nature 426: 454-460.

79. Brand, D. D., K. A. Latham, and E. F. Rosloniec. 2007. Collagen-induced arthritis. Nat. Protoc. 2: 1269-1275.

80. Hu, Y. L., D. P. Metz, J. Chung, G. Siu, and M. Zhang. 2009. B7RP-1 blockade ameliorates autoimmunity through regulation of follicular helper T cells. J. Immunol. 182: 14211428.

81. Frohman, E. M., M. K. Racke, and C. S. Raine. 2006. Multiple sclerosis--the plaque and its pathogenesis. N. Engl. J. Med. 354: 942-955.

82. Ramagopalan, S. V., J. C. Knight, and G. C. Ebers. 2009. Multiple sclerosis and the major histocompatibility complex. Curr. Opin. Neurol. 22: 219-225.

83. Damsker, J. M., A. M. Hansen, and R. R. Caspi. 2010. Th1 and Th17 cells: adversaries and collaborators. Ann. N. Y. Acad. Sci. 1183: 211-221.

84. Weber, M. S., B. Hemmer, and S. Cepok. 2011. The role of antibodies in multiple sclerosis. Biochim. Biophys. Acta 1812: 239-245.

85. Zhou, D., R. Srivastava, S. Nessler, V. Grummel, N. Sommer, W. Bruck, H. P. Hartung, C. Stadelmann, and B. Hemmer. 2006. Identification of a pathogenic antibody response to native myelin oligodendrocyte glycoprotein in multiple sclerosis. Proc. Natl. Acad. Sci. U. S. A. 103: 19057-19062.

86. Tzartos, J. S., M. J. Craner, M. A. Friese, K. B. Jakobsen, J. Newcombe, M. M. Esiri, and L. Fugger. 2011. IL-21 and IL-21 receptor expression in lymphocytes and neurons in multiple sclerosis brain. Am. J. Pathol. 178: 794-802.

87. Domingues, H. S., M. Mues, H. Lassmann, H. Wekerle, and G. Krishnamoorthy. 2010. Functional and pathogenic differences of Th1 and Th17 cells in experimental autoimmune encephalomyelitis. PLoS One 5: e15531.

88. Miller, S. D., W. J. Karpus, and T. S. Davidson. 2010. Experimental autoimmune encephalomyelitis in the mouse. Curr. Protoc. Immunol. Chapter 15: Unit 15.1.

89. Magliozzi, R., O. Howell, A. Vora, B. Serafini, R. Nicholas, M. Puopolo, R. Reynolds, and F. Aloisi. 2007. Meningeal B-cell follicles in secondary progressive multiple sclerosis associate with early onset of disease and severe cortical pathology. Brain 130: 1089-1104.

90. Peters, A., L. A. Pitcher, J. M. Sullivan, M. Mitsdoerffer, S. E. Acton, B. Franz, K. Wucherpfennig, S. Turley, M. C. Carroll, R. A. Sobel, E. Bettelli, and V. K. Kuchroo. 2011. Th17 cells induce ectopic lymphoid follicles in central nervous system 
tissue inflammation. Immunity 35: 986-996.

91. Mahad, D. H., B. D. Trapp, and H. Lassmann. 2015. Pathological mechanisms in progressive multiple sclerosis. Lancet Neurol. 14: 183-193.

92. Sadatipour, B. T., J. M. Greer, and M. P. Pender. 1998. Increased circulating antiganglioside antibodies in primary and secondary progressive multiple sclerosis. Ann. Neurol. 44: 980-983.

93. Hauser, S. L., and J. R. Oksenberg. 2006. The neurobiology of multiple sclerosis: genes, inflammation, and neurodegeneration. Neuron 52: 61-76.

94. Kaushansky, N., D. M. Altmann, S. Ascough, C. S. David, H. Lassmann, and A. Ben-Nun. 2009. HLA-DQB1*0602 determines disease susceptibility in a new "humanized" multiple sclerosis model in HLA-DR15 (DRB1*1501;DQB1*0602) transgenic mice. J. Immunol. 183: 3531-3541.

95. Kaushansky, N., D. M. Altmann, C. S. David, H. Lassmann, and A. Ben-Nun. 2012. DQB1*0602 rather than DRB1*1501 confers susceptibility to multiple sclerosis-like disease induced by proteolipid protein (PLP). J. Neuroinflammation. 9: 29 .

96. Conti-Fine, B. M., M. Milani, and H. J. Kaminski. 2006. Myasthenia gravis: past, present, and future. J. Clin. Invest 116: 2843-2854.

97. Nichols, P., R. Croxen, A. Vincent, R. Rutter, M. Hutchinson, J. Newsom-Davis, and D. Beeson. 1999. Mutation of the acetylcholine receptor epsilon-subunit promoter in congenital myasthenic syndrome. Ann. Neurol. 45: 439-443.

98. Luo, C., Y. Li, W. Liu, H. Feng, H. Wang, X. Huang, L. Qiu, and J. Ouyang. 2013. Expansion of circulating counterparts of follicular helper T cells in patients with myasthenia gravis. $J$. Neuroimmunol. 256: 55-61.

99. Fuchs, S., R. Aricha, D. Reuveni, and M. C. Souroujon. 2014. Experimental Autoimmune Myasthenia Gravis (EAMG): from immunochemical characterization to therapeutic approaches. J. Autoimmun. 54: 51-59.

100. Wu, B., E. Goluszko, R. Huda, E. Tuzun, and P. Christadoss. 2013. Experimental autoimmune myasthenia gravis in the mouse. Curr. Protoc. Immunol. Chapter 15: Unit 15.8.

101. Xin, N., L. Fu, Z. Shao, M. Guo, X. Zhang, Y. Zhang, C. Dou, S. Zheng, X. Shen, Y. Yao, J. Wang, J. Wang, G. Cui, Y. Liu, D. Geng, C. Xiao, Z. Zhang, and R. Dong. 2014. RNA interference targeting Bcl-6 ameliorates experimental autoimmune myasthenia gravis in mice. Mol. Cell. Neurosci. 58: 85-94.

102. Borchers, A. T., S. M. Naguwa, C. L. Keen, and M. E. Gershwin. 2003. Immunopathogenesis of Sjogren's syndrome. Clin. Rev. Allergy Immunol. 25: 89-104.

103. Chaigne, B., G. Lasfargues, I. Marie, B. Huttenberger, C. Lavigne, S. Marchand-Adam, F. Maillot, and E. Diot. 2015.
Primary Sjogren's syndrome and occupational risk factors: A case-control study. J. Autoimmun. 60: 80-85.

104. Priori, R., E. Medda, F. Conti, E. A. Cassara, M. G. Sabbadini, C. M. Antonioli, R. Gerli, M. G. Danieli, R. Giacomelli, M. Pietrogrande, G. Valesini, and M. A. Stazi. 2007. Risk factors for Sjogren's syndrome: a case-control study. Clin. Exp. Rheumatol. 25: 378-384.

105. Aggarwal, R., J. M. Anaya, K. A. Koelsch, B. T. Kurien, and R. H. Scofield. 2015. Association between secondary and primary Sjogren's syndrome in a large collection of lupus families. Autoimmune Dis. 2015: 298506.

106. Ben-Chetrit, E., R. Fischel, and A. Rubinow. 1993. Anti-SSA/ Ro and anti-SSB/La antibodies in serum and saliva of patients with Sjogren's syndrome. Clin. Rheumatol. 12: 471-474.

107. Jin, L., D. Yu, X. Li, N. Yu, X. Li, Y. Wang, and Y. Wang. 2014. CD4+CXCR5+ follicular helper T cells in salivary gland promote $\mathrm{B}$ cells maturation in patients with primary Sjogren's syndrome. Int. J. Clin. Exp. Pathol. 7: 1988-1996.

108. Li, X. Y., Z. B. Wu, J. Ding, Z. H. Zheng, X. Y. Li, L. N. Chen, and P. Zhu. 2012. Role of the frequency of blood CD4(+) CXCR5(+) CCR6(+) T cells in autoimmunity in patients with Sjogren's syndrome. Biochem. Biophys. Res. Commun. 422: 238-244.

109. Park, Y. S., A. E. Gauna, and S. Cha. 2015. Mouse Models of Primary Sjogren's Syndrome. Curr. Pharm. Des 21: 23502364.

110. Manning, D. D., N. D. Reed, and C. F. Shaffer. 1973. Maintenance of skin xenografts of widely divergent phylogenetic origin of congenitally athymic (nude) mice. $J$. Exp. Med. 138: 488-494.

111. Larsen, C. P., S. J. Knechtle, A. Adams, T. Pearson, and A. D. Kirk. 2006. A new look at blockade of T-cell costimulation: a therapeutic strategy for long-term maintenance immunosuppression. Am. J. Transplant. 6: 876-883.

112. Ziolkowski, J., L. Paczek, M. Niewczas, G. Senatorski, U. Oldakowska-Jedynak, J. Wyzgal, B. Foroncewicz, K. Mucha, J. Zegarska, P. Nyckowski, K. Zieniewicz, W. Patkowski, M. Krawczyk, B. Ziarkiewicz-Wroblewska, and B. Gornicka. 2003. Effect of immunosuppressive regimen on acute rejection and liver graft function. Transplant. Proc. 35: 22812283.

113. Colvin, R. B., and R. N. Smith. 2005. Antibody-mediated organ-allograft rejection. Nat. Rev. Immunol. 5: 807-817.

114. Jindra, P. T., A. Hsueh, L. Hong, D. Gjertson, X. D. Shen, F. Gao, J. Dang, P. S. Mischel, W. M. Baldwin, III, M. C. Fishbein, J. W. Kupiec-Weglinski, and E. F. Reed. 2008. AntiMHC class I antibody activation of proliferation and survival signaling in murine cardiac allografts. J. Immunol. 180: 22142224.

115. Clatworthy, M. R. 2011. Targeting B cells and antibody in 
transplantation. Am. J. Transplant. 11: 1359-1367.

116. Gorbacheva, V., K. Ayasoufi, R. Fan, W. M. Baldwin, III, and A. Valujskikh. 2015. B cell activating factor (BAFF) and a proliferation inducing ligand (APRIL) mediate CD40independent help by memory CD4 T cells. Am. J. Transplant. 15: 346-357.

117. Gorbacheva, V., R. Fan, X. Wang, W. M. Baldwin, III, R. L. Fairchild, and A. Valujskikh. 2015. IFN-gamma production by memory helper $\mathrm{T}$ cells is required for CD40-independent alloantibody responses. J. Immunol. 194: 1347-1356.

118. Lynch, R. J., I. A. Silva, B. J. Chen, J. D. Punch, M. Cascalho, and J. L. Platt. 2013. Cryptic B cell response to renal transplantation. Am. J. Transplant. 13: 1713-1723.

119. de Graav, G. N., M. Dieterich, D. A. Hesselink, K. Boer, M.
C. Clahsen-van Groningen, R. Kraaijeveld, N. H. Litjens, R. Bouamar, J. Vanderlocht, M. Tilanus, I. Houba, A. Boonstra, D. L. Roelen, F. H. Claas, M. G. Betjes, W. Weimar, and C. C. Baan. 2015. Follicular T helper cells and humoral reactivity in kidney transplant patients. Clin. Exp. Immunol. 180: 329340.

120. Flynn, R., J. Du, R. G. Veenstra, D. K. Reichenbach, A. Panoskaltsis-Mortari, P. A. Taylor, G. J. Freeman, J. S. Serody, W. J. Murphy, D. H. Munn, S. Sarantopoulos, L. Luznik, I. Maillard, J. Koreth, C. Cutler, R. J. Soiffer, J. H. Antin, J. Ritz, J. A. Dubovsky, J. C. Byrd, K. P. MacDonald, G. R. Hill, and B. R. Blazar. 2014. Increased T follicular helper cells and germinal center B cells are required for cGVHD and bronchiolitis obliterans. Blood 123: 3988-3998. 